\title{
Reuna
}

\section{MOTIVAÇÃO E RETENÇÃO DE DOCENTES EM INSTITUIÇÃO DE ENSINO SUPERIOR COMUNITÁRIA}

\section{MOTIVATION AND RETENTION OF PROFESSORS IN COMMUNITY HIGHER EDUCATION INSTITUTION}

\author{
http://dx.doi.org/10.21714/2179-8834/2017v22n4p54-74
}

\author{
Eliane Salete Filippim \\ Universidade do Oeste de Santa Catarina (Unoesc), Brasil. \\ E-mail: eliane.filippim@unoesc.edu.br \\ Silvio Santos Júnior \\ Universidade do Oeste de Santa Catarina (Unoesc), Brasil. \\ E-mail: silviosantos.junior@unoesc.edu.br \\ Lígia Krühs Zulian \\ Universidade do Oeste de Santa Catarina (Unoesc), Brasil. \\ E-mail: ligia.zulian@unoesc.edu.br \\ Fábio Lazzarotti \\ Universidade do Oeste de Santa Catarina (Unoesc), Brasil. \\ E-mail: fabio.lazzarotti@unoesc.edu.br
}

Submissão: 08 Maio 2017 Publicação: 09 Abril 2017. Sistema de avaliação: Double blind review. Centro Universitário UNA, Belo Horizonte - MG, Brasil. Editor geral: Prof. Dr. Gustavo Quiroga Souki

Este artigo encontra-se disponível nos seguintes endereços eletrônicos:

http://revistas.una.br/index.php/reuna/article/view/922

http://dx.doi.org/10.21714/2179-8834/2017v22n4p54-74

\section{RESUMO}

Um dos principais desafios que as organizações enfrentam é a retenção de pessoas, uma vez que nessas se encontra o conhecimento e as habilidades necessárias para a realização da missão institucional. Este desafio se torna particularmente instigante, quando se trata de uma Instituição de Ensino Superior (IES), dada à complexidade das atividades envolvidas de ensino, pesquisa e extensão. Neste sentido, o objetivo geral do estudo foi compreender o que motiva o docente a ingressar e a permanecer atuando em IES Comunitária e em Programas de pós-graduação stricto sensu (Mestrado e Doutorado). Para este fim foi desenvolvido estudo de caso, por meio da aplicação de questionário e análise de documentos. Os resultados observados demonstram que entre os fatores que motivam docentes a ingressar e/ou permanecer trabalhando em IES estão: a possibilidade de desenvolver pesquisa e a autonomia que podem usufruir. Entre os fatores que mais os desmotivam estão àqueles ligados ao salário e ao ambiente de trabalho, notadamente, o relacionamento interpessoal.

Palavras-chave: Motivação. Retenção. Docentes. Instituição de Ensino Superior. 


\begin{abstract}
One of the main challenges faced by organizations is the retention of people, once the knowledge and skills necessary to accomplish the institutional task are found on them. This challenge becomes particularly instigating when it is about a Higher Education Institution $(\mathrm{HEI})$, considering the complexity of the activities involved in teaching, research and extension activities. Therefore, the general objective was to understand what motivates professors to enter and keep working in Community $\mathrm{HEI}$ and in stricto sensu graduate programs (masters and doctorate). To this end, a case study was developed through the application of questionnaire and document analysis. The results show that among the factors that motivate professors to enter and/or keep working in HEls are: the possibility of developing research and the autonomy they can enjoy. Among the most demotivating factors are the ones related to salary and work environment, clearly the interpersonal relationship.
\end{abstract}

Keywords: Motivation. Retention. Professors. Higher Education Institution.

\title{
1. Introdução
}

Diante de um cenário dinâmico que exige novos perfis dos profissionais, as organizações têm se dedicado à atração de profissionais portadores de competências alinhadas a este ambiente de constantes mudanças. Contudo, apenas atrair este perfil de trabalhador não basta, é necessário também estabelecer políticas, que favoreçam a motivação e a retenção deles nos quadros organizacionais. Isto é particularmente complexo em organizações, cujo fim é a educação.

Para uma Instituição de Ensino Superior (IES) estabelecer políticas adequadas de atração e retenção de profissionais docentes se constitui em um desafio primordial, uma vez que precisa levar em consideração as especificidades próprias de uma organização com objetivos múltiplos e especializados, voltados para a criação e a difusão do conhecimento, como é o caso de uma universidade.

Além da inerente complexidade, a universidade pode ser vista como uma organização que pouco motiva seus docentes, gerando rotatividade. Nem toda rotatividade é problemática, mas passa a ser problema, quando boa parte dela é voluntária, disfuncional e poderia ser evitada (KLEIN; MASCARENHAS, 2016). A rotatividade de profissionais, em uma organização, quando excessiva, acarreta disfunções, uma vez que, para Agnolin (2016), ela gera custos de contratação, tarefas que não são executadas adequadamente, falta de qualidade ou de tempo adequados para o aprendizado e, sobretudo, produz defasagens no conhecimento perdido, cada vez que a organização perde um de seus trabalhadores.

Agnolin (2016), ao examinar a questão da retenção do conhecimento organizacional, salienta que os conhecimentos adquiridos, desenvolvidos e armazenados pelos trabalhadores, que saem da organização, seguem com eles forçando-a a reiniciar o processo de geração de conhecimento. A rotatividade é, particularmente, nociva à IES, quando se trata de docentes vinculados aos programas stricto sensu, visto que a estabilidade é critério de avaliação da Coordenação de Aperfeiçoamento de Pessoal de Nível Superior (CAPES). 
As IES, e em especial, os cursos de Mestrado e Doutorado, possuem um papel chave no desenvolvimento tecnológico e social do país. De acordo com a Capes (BRASIL, 2011), a pós-graduação brasileira, ao mesmo tempo em que compõe a organização da educação nacional, serve de base para a formação de recursos humanos aptos para atuarem nos diferentes setores da sociedade. Assim, formando recursos humanos qualificados a contribuir para o desenvolvimento da ciência e tecnologia no país (BRASIL, 2011), torna-se relevante para as IES atrair e manter docentes altamente qualificados.

De acordo com a Capes (BRASIL 2011), seguindo o Art. 52 da Lei no 9.394/96, as universidades se caracterizam pela indissociabilidade das atividades de ensino, pesquisa e de extensão e por terem, obrigatoriamente, em seu quadro docente, um terço de professores com titulação de mestrado e doutorado e um terço de professores em regime de tempo integral. Para atender a esta lei, as universidades gozam de autonomia para contratar, dispensar e estabelecer planos de carreira para seus docentes.

Assim, o processo de atração e de retenção de docentes em Programas de Pós-graduação stricto sensu (Mestrado e Doutorado) vem sendo discutido nas IES, de maneira a encontrar formas para melhor gerir este processo. Segundo Stewart et al. (2011), a rotatividade mede a intenção de um profissional de sair do emprego atual e os resultados dessa medida podem ajudar os gestores a desenvolver ações capazes de fomentar a permanência dos profissionais necessários ao cumprimento da missão organizacional. A observação dos elementos, que contribuem para a intenção de permanecer atuando em uma IES, especialmente, em Programas de Pós-graduação, pode ser tanto ou mais importante, quando se trata de uma IES de caráter comunitário que, a rigor, não é pública, mas tampouco privada. Uma IES comunitária, como é o caso da universidade foco deste estudo, se caracteriza pela natureza fundacional, de caráter filantrópico, prestadora de serviços públicos, de interesse coletivo e sem fins lucrativos.

Neste contexto, o estudo assume relevância ao examinar a questão da motivação e da retenção docente como fator estratégico para manter a perenidade e a qualidade de Programas de Pós-graduação, favorecendo o atendimento da missão institucional das IES. Desta maneira, a pesquisa teve como questões de partida: o que leva o docente a ingressar e a permanecer em IES Comunitárias? Quais são os elementos que favorecem a motivação e a retenção de docentes em IES e a atuar em Programas de pós-graduação stricto sensu? Para atender a estas questões, o objetivo geral do estudo foi: compreender quais são os fatores motivacionais dos docentes para atuarem em IES Comunitária e em Programas de pós-graduação stricto sensu (Mestrado e Doutorado).

Considera-se que uma IES gerencia recursos raros como é o caso do conhecimento. É possível que aspectos relativos ao gerenciamento do conhecimento possam ser determinantes na retenção de trabalhadores de uma organização, pois a retenção dos funcionários inclui um conjunto de políticas e de práticas de gestão de pessoas, que envolvem o comportamento dos gestores e a atuação da área de recursos humanos (GARCIA; COLTRE, 2017).

Desta maneira, após esta introdução se apresenta a revisão bibliográfica, que subsidia o estudo, e na qual se buscou identificar os fatores intrínsecos e extrínsecos, 
que motivam os colabores a ingressar e permanecer em uma organização. Na sequência são demonstrados os procedimentos metodológicos utilizados para este estudo, em que se caracteriza a Instituição caso, a qual foi investigada por meio de análises documentais e uma survey aplicada a docentes e ex-docentes. Na seção 4 são apresentados os achados do estudo, que foram analisados qualitativamente, buscando triangular os dados da survey, com documentos e com elementos apontados pela revisão de literatura, embora na apresentação dos dados, sempre que pertinente, serviu-se da estatística Qui-quadrado para demonstrar semelhanças ou diferenças encontradas. Ao final são apresentadas as considerações finais e as referências utilizadas no estudo.

\section{Atração e retenção da força de trabalho}

Diversos fatores influem na atração e retenção da força de trabalho, como, por exemplo, a satisfação das necessidades humanas básicas, as condições de trabalho, o relacionamento com os colegas e os gestores, além de fatores diretamente ligados ao trabalho, como: o reconhecimento, a satisfação e a oportunidade de progresso funcional e pessoal (GOMES; QUELHAS, 2003). Um dos fatores, que propicia a retenção, é a motivação, por isto, a compreensão de fatores motivacionais requer a utilização de uma diversidade de abordagens e também recomenda estudos teóricos e empíricos (GODOI; FREITAS; CARVALHO, 2011).

De acordo com Bzuneck (2009), o termo motivação corresponde a um motivo que impulsiona o sujeito a agir, que determina o seu comportamento, desejos e sentimentos, podendo ser em função de fatores internos ou externos. Ao realizar uma atividade, que lhe proporciona resultados positivos, gerando sensação de bem-estar, suas reações serão na direção de continuar em tal atividade, entretanto, na medida em que os resultados obtidos são negativos e não proporcionam nenhum estímulo prazeroso, aos poucos, essa ação perderá a função não produzindo bons resultados, diminuindo a motivação e o interesse do sujeito.

São múltiplos os fatores motivacionais e Latham e Pinder (2005) declaram que a motivação é um processo psicológico complexo, que resulta de uma interação entre o sujeito e o ambiente. As características de personalidade e as expectativas são particulares, afetando de maneira diferente aos sujeitos (BRAGA JÚNIOR; SANTOS; CARVALHO; SILVA; SILVA, 2013).

A motivação vem sendo investigada por diferentes áreas do conhecimento. No contexto educacional tem sido estudada pela Psicologia, resultando na criação de teorias e abordagens sobre este tema (BZUNECK, 2009). Trata-se de um fenômeno pessoal, particular e único para cada sujeito, acarretando que "ninguém consegue motivar ninguém" (BERGAMININI, 2002-2003, p.67). Assim, o que resta ao alcance da organização é a criação de ambiente favorável à motivação e, por este motivo, a pesquisa sobre o que os sujeitos declaram que os motiva se torna relevante para embasar a elaboração de políticas de atração e de retenção de pessoas.

Este estudo segue o entendimento de Klein e Mascarenhas (2016), quando argumentam que os fatores motivacionais são aqueles direcionadores do comportamento do sujeito, intrínsecos à natureza do seu trabalho, ou extrínsecos ao trabalho, relacionados às condições do ambiente. Ainda, de acordo com os autores, a clássica teoria dos dois fatores motivacionais de Herzberg $(1964,1968)$ aponta que a 
oferta dos fatores extrínsecos satisfaz necessidades básicas dos sujeitos, reduzindo fontes de desconforto que, se presentes, geram insatisfação e podem influenciar a evasão do emprego. Apresentam como exemplos de fatores extrínsecos: ambiente organizacional, segurança e saúde no trabalho, salários, remunerações e benefícios. Já os fatores intrínsecos estão relacionados à realização do trabalho, satisfazem necessidades simbólicas, como o prazer e a identificação com o trabalho, a busca por desenvolvimento pessoal e profissional, o status do cargo, a busca por responsabilidade, a autonomia na execução do trabalho, o reconhecimento dos colegas, entre outros. Segundo os autores, a motivação intrínseca seria mais genuína, pois deriva da energia motivacional e dos aspectos simbólicos diretamente atrelados à própria realização do trabalho.

Werlang; Bianchi; Vendruscolo (2015) organizaram os fatores motivacionais intrínsecos e extrínsecos da seguinte maneira: a) Motivação Intrínseca - vivenciar estímulos (fazer algo a fim de experimentar sensações); intrínseca para realização (fazer algo pelo prazer e pela realização pessoal e descoberta de coisas novas); direcionada para saber (fazer algo pela satisfação de aprender e por entender o que quer do futuro. b) Motivação Extrínseca - controle externo (sentir-se pressionado por algo ou por alguém); introjeção (fazer algo, porque se pressiona a fazer); identificação (fazer algo, porque decidiu fazer).

Assim, de acordo com Marchiori et al. (2006), os fatores motivadores dizem respeito à realização, ao reconhecimento, à responsabilidade e ao avanço e ao crescimento; e os fatores higiênicos/extrínsecos se referem à segurança no trabalho, à vida pessoal, às relações interpessoais, às condições de trabalho, ao status e supervisão e às condições materiais como o salário e os benefícios sociais. Observando a motivação para o desempenho acadêmico, em geral, aspecto relacionado à atividade docente, Taylor (2014), observou a forte relevância da motivação intrínseca.

Claro e Profeta (2015) estudaram como é tratada a questão dos Benefícios Sociais (BS) em IES, e elencaram BS oferecidos por essas: Creche; Exame Médico Periódico; Médico do Trabalho; Refeitório/Restaurante; Vale Transporte; Adiantamento Salarial; Aluguel de casa; Assistência Jurídica; Assistência MédicoHospitalar/Plano de Saúde; Assistência Odontológica; Atividades Recreativas e Culturais; Assistência Social; Complemento de Aposentadoria/Plano de Seguridade Social; Cursos Variados; entre outros. Os autores apontam que investir em Benefícios Sociais e na melhoria da Qualidade de Vida no Trabalho para os trabalhadores pode levar à maior atratividade/retenção de profissionais nas organizações. Contudo, concluem que as IES se limitam a oferecer benefícios básicos ou apenas aqueles previstos em convenção coletiva de trabalho. Os autores apontam que dentre os dez benefícios mais ofertados, pelo menos cinco deles (Convênio Médico, Exame Médico Periódico, Médico do Trabalho, Licença sem Remuneração e Vale Transporte) são previstos em legislação específica e os outros cinco implicam em algum investimento, por parte da IES (E-mail, Estacionamento, Plano de Carreira, Confraternização de Natal e Refeitório/ Restaurante).

Especificamente, no campo da educação, Ribeiro e Sant'Anna (2015) apontam que se demanda das organizações que elas definam, de forma clara, quais são suas expectativas em relação aos docentes e quais perspectivas vão ofertar a eles. Os autores analisaram diversos estudos e sintetizaram os fatores considerados relevantes para a retenção de pessoas: desenvolvimento profissional e continuado, RELUNA, Belo Horizonte - MG, Brasil, v.23, n.I, p.54-74, Jan. - Mar.. 2018 - ISSN 2179-8834 
oportunidades de treinamento, de flexibilidade no trabalho e na carga horária, variedade de tarefas, criatividade, remuneração e benefícios, plano de cargos e salários e critérios de ascensão, clima organizacional e relacionamento interpessoal, satisfação pelo trabalho, reconhecimento profissional, comunicação interna e abertura para o diálogo, feedback, relacionamento com a chefia, autonomia, nível de desafio, envolvimento e participação nas decisões, condições físicas e recursos materiais e imagem da organização.

$\mathrm{Na}$ mesma linha, Lopes et al. (2015) apregoam que os indivíduos possuem níveis e tipos diferentes de motivação, relacionados às atitudes subjacentes e aos objetivos que dão origem à ação. Outro aspecto, que influencia a motivação dos funcionários, são os valores organizacionais, afetando sua disposição de permanecer ou não na organização (CERIBELI; GONÇALVES, 2015).

Considerando que a rotatividade se configura como a proporção de empregados que deixa a organização, em determinado período (SIQUEIRA; ALVES, 2016), para reduzi-la faz-se necessário empreender ações, que contribuam para o bem-estar e para a satisfação dos trabalhadores. Quando os funcionários mais capacitados, experientes e detentores de conhecimentos importantes saem voluntariamente, a organização incorre em uma série de custos (tangíveis e intangíveis), que afetam sua produtividade (ALLEN et al., 2010).

Os trabalhadores deixam as organizações por uma variedade de razões, desde a busca por emprego mais estável, e/ou que remunere melhor, até a necessidade de se ajustar a fatores conjunturais externos à vontade do sujeito (como acompanhar o cônjuge). Entre as razões mais evidentes da saída, merecem destaque os níveis salariais, a satisfação com o trabalho e a necessidade de estabilidade, que acompanha muitos sujeitos. Ribeiro e Sant'Anna (2015) realizaram pesquisa que evidenciou grande número de respondentes que busca a estabilidade no emprego como prioridade na escolha de uma organização para trabalhar e/ou permanecer. Os autores chamam atenção para a atração exercida pelo setor público, tendo em vista a possibilidade de manutenção do emprego (estabilidade), independentemente, de possíveis crises (externas ou diretamente ligadas à organização), de mudanças organizacionais ou de outros fatores relacionados ao perfil do empregado, que poderiam desaguar em demissão.

Outros fatores relacionados à motivação e à desmotivação, por permanecer em uma carreira, estão aqueles relacionados ao gênero, como o gênero, pois, conforme demonstrado por Reuben; Sapienza; e Zingales (2014), os estereótipos podem pesar sobre a expectativa de desempenho, sobretudo, em relação às mulheres, resultando em discriminação delas na ascensão na carreira. As diferenças de gênero fornecem possível explicação para a trajetória da carreira, sendo que representa uma parcela de cerca de $20 \%$ na competitividade, a favor do sexo masculino, de acordo com Buser; Niederle; e Oosterbeek (2014).

Apesar da relevância da compensação de quais fatores retém os profissionais na organização, Allen et al. (2010) advertem que estes fatores perdem relevância quando outros mais ligados à decisão individual de sair do emprego são considerados, pois a saída pode também ser motivada, quando oportunidades externas mais atraentes se apresentam para o sujeito. As carreiras ditas sem fronteiras (BRAVO, 2017) levam os sujeitos à mobilidade e afetam a decisão por permanecer ou não na organização.

REUNA, Belo Horizonte - MG, Brasil, v.23, n.I, p.54-74, Jan. - Маг.. 2018 - ISSN 2179-8834 


\section{Procedimentos metodológicos}

Este estudo se classifica como qualitativo, uma vez que parte da captura, descrição e análise das percepções dos sujeitos de pesquisa acerca de sua motivação para ingressar e permanecer ou sair de IES comunitária. Embora os dados tenham sido agrupados, classificados e se apresentem alguns testes estatísticos, a natureza do estudo quanto à abordagem do problema é qualitativa, pois a análise dos dados procura mostrar a relação entre sujeito e mundo, de forma indutiva, a partir de dados ditados pela visão pessoal e subjetiva dos participantes da pesquisa.

Configura-se como estudo de caso único, seguindo a classificação de Yin (2010), que se configura, entre outras situações, a um caso representativo de uma situação. As características especiais de uma IES comunitária motivaram os pesquisadores a eleger este tipo de organização, pois esta (e suas similares) tem importante participação no sistema de Ensino Superior do interior Estado de Santa Catarina, Sul do Brasil. A escolha recaiu, portanto, sobre uma IES comunitária, doravante denominada "IES caso". Esta IES foi criada pelo poder público municipal e pertence ao Sistema Acafe (Associação Catarinense das Fundações Educacionais). De acordo com dados fornecidos pela IES caso, essa surgiu no ano de 1972 com o objetivo de contribuir com o desenvolvimento do Oeste Catarinense e preencher uma lacuna deixada pelo Estado no oferecimento de Ensino Superior no interior de Santa Catarina (SC). A IES caso possui o status de Universidade desde 1996 e é formada por campi distribuídos em área geográfica de $27.255,5 \mathrm{~km}^{2}$, na qual estão 118 municípios, com 1.116.766 habitantes. Realiza suas atividades de ensino, de pesquisa e de extensão, por meio de 41 diferentes cursos de graduação, contando com aproximadamente 15 mil alunos. Possui cerca de 900 docentes e mais de 600 funcionários. No stricto sensu, possui seis cursos de mestrado e um doutorado, todos recomendados pela Capes. Embora a IES caso permitisse a divulgação de seu nome, os pesquisadores optaram por omitir esta informação mesmo que alguns dados - de necessária apresentação - acabem por favorecer a sua identificação.

A IES caso foi eleita também devido a sua localização, interior do Estado de SC, em uma região mais afastada da capital e, por isto mesmo, com maiores dificuldades para atrair docentes (Doutores) para atuar em Programas de pósgraduação stricto sensu (Mestrado e Doutorado). Os pesquisadores acreditam que dadas as dimensões continentais do país, observar o tema do estudo em organização do interior da federação poderia ser salutar para a compreensão sobre os fatores, que podem atrair/reter Doutores para Mestrados e Doutorados das IES ali localizadas.

A IES caso relatou aos pesquisadores desligamento de docentes dos seus Programas, evidenciado, sobretudo, no período de 2009 a 2015, quando 111 docentes doutores se desligaram, produzindo perdas significativas para os seus projetos de Mestrado e Doutorado. O Quadro 1 apresenta o percentual de rotatividade dos docentes, que se desligaram da IES caso, no período de 2009 a 2015. 
Quadro 1 - Rotatividade de docentes de janeiro de 2009 a dezembro de 2015.

\begin{tabular}{|c|c|c|c|c|c|c|c|}
\hline Ano & Semestre & Campus 1 & Campus 2 & Campus 3 & Campus 4 & Campus 5 & Ro (\%) \\
\hline & Primeiro & 13,5 & 27,3 & 0,0 & 20,0 & 0,0 & 7,1 \\
\hline \multirow[t]{2}{*}{2009} & Segundo & 5,6 & 44,4 & 0,0 & 10,0 & 33,3 & 9,6 \\
\hline & Média anual & 9,5 & 35,9 & 0,0 & 15,0 & 16,7 & 15,4 \\
\hline & Primeiro & 12,5 & 0,0 & 0,0 & 0,0 & 0,0 & 2,8 \\
\hline \multirow[t]{2}{*}{2010} & Segundo & 5,9 & 14,3 & 40,0 & 0,0 & 66,7 & 12,1 \\
\hline & Média anual & 9,2 & 7,1 & 20,0 & 0,0 & 33,3 & 13,9 \\
\hline \multirow{3}{*}{2011} & Primeiro & 15,2 & 12,5 & 0,0 & 0,0 & 0,0 & 4,3 \\
\hline & Segundo & 3,2 & 11,1 & 22,2 & 10,0 & 0,0 & 6,3 \\
\hline & Média anual & 9,2 & 11,8 & 11,1 & 5,0 & 0,0 & 7,4 \\
\hline \multirow{3}{*}{2012} & Primeiro & 0,0 & 0,0 & 7,1 & 7,1 & 0,0 & 4,7 \\
\hline & Segundo & 11,9 & 14,3 & 4,8 & 0,0 & 0,0 & 6,8 \\
\hline & Média anual & 6,0 & 7,1 & 6,0 & 3,6 & 0,0 & 4,5 \\
\hline \multirow{3}{*}{2013} & Primeiro & 5,7 & 16,7 & 17,6 & 13,3 & 0,0 & 8,9 \\
\hline & Segundo & 0,0 & 0,0 & 11,1 & 7,7 & 7,7 & 6,8 \\
\hline & Média anual & 2,9 & 8,3 & 14,4 & 10,5 & 3,8 & 8,0 \\
\hline \multirow{3}{*}{2014} & Primeiro & 7,9 & 6,3 & 10,0 & 0,0 & 0,0 & 7,2 \\
\hline & Segundo & 7,3 & 6,7 & 34,8 & 16,7 & 6,3 & 12,1 \\
\hline & Média anual & 7,6 & 6,5 & 22,4 & 8,3 & 3,1 & 9,6 \\
\hline \multirow{4}{*}{2015} & Primeiro & 2,2 & 0,0 & 27,3 & 0,0 & 5,0 & 9,0 \\
\hline & Segundo & 10,2 & 15,8 & 11,5 & 10,5 & 5,3 & 11,2 \\
\hline & Média anual & 6,2 & 7,9 & 19,4 & 5,3 & 5,1 & 8,8 \\
\hline & Total & 7,2 & 12,1 & 13,3 & 6,8 & 8,9 & 9,7 \\
\hline
\end{tabular}

Fonte: Dados fornecidos pela IES caso (2016).

A classificação do índice de rotatividade seguiu os mesmos parâmetros estabelecidos no estudo de Campos e Malik (2008), sendo a fórmula de cálculo estabelecida para o índice de rotatividade (Ro) na IES caso:

Ro $=$ Número de desligamentos no período X 100

Número total de funcionários no final do período

O período de 2009 a 2015 foi enfatizado, pois coincide com a expansão, no Brasil, do sistema federal de ensino, por meio da criação e interiorização de Institutos e Universidades Federais, o que demandou a realização de inúmeros concursos públicos para os quais os docentes evadidos da IES caso se candidataram e, com frequência, obtiveram aprovação.

Para coleta de dados foram utilizados documentos disponibilizados para consulta dos pesquisadores pela IES caso e, também, questionário dirigido aos atuais docentes doutores e aqueles com o mesmo título, que saíram da IES caso. O questionário tinha 52 questões, de diferentes tipos (escolha simples, múltipla, escalar, aberta, entre outras), divididas em sete blocos, que procuraram abstrair dos sujeitos da pesquisa: 1) informações demográficas e percepções gerais; 2) relações com a IES em que exercem atividades; 3) condições de trabalho e carreira na IES; 4) razões para trabalhar na IES; 5) percepção de suas funções na IES; 6) motivos do 
desligamento da IES do caso (destinada apenas aos docentes egressos); e, por fim, um bloco 7) destinado apenas aos pesquisados, que atuam no stricto sensu. Não se apresenta aqui os constructos dos quais as questões derivam por exiguidade de espaço, informa-se, entretanto, que o questionário foi elaborado com base na revisão da literatura e que foram realizados procedimentos para sua validação.

No processo de coleta de dados, por meio da survey, tentou-se a realização de um censo com todos os professores, que atuam ou atuaram na IES caso. em uma primeira etapa foram enviados 264 e-mails (164 para doutores, que atuam na IES e 100 para outros, que atuaram ente 2009 e 2015). em uma segunda etapa, com objetivo de aumentar a taxa de resposta dos docentes externos, o procedimento de envio foi repetido e foi resguardada a cautela para não haver duplicidade de respostas, a taxa de resposta global final ficou em $32,3 \%$. Assim, a pesquisa tem duas unidades de análise: a) professores doutores, que ainda atuam na IES caso; e b) professores doutores, que atuaram na IES caso, mas que atualmente estão desligados.

Os dados obtidos, por meio da aplicação do questionário, foram tabulados com ajuda de software estatístico. A análise ocorreu por meio da triangulação deles com os dados documentais e com elementos apontados pela revisão de literatura. Neste texto estão apresentados nos seguintes tópicos de análise: perfil dos sujeitos de pesquisa; motivação para o ingresso e permanência na IES; motivação para atuar no Mestrado ou Doutorado. Na análise, quando pertinente, buscou-se analisar se havia visões distintas entre as duas unidades de análise, avaliadas por meio do teste Quiquadrado. Observa-se que, em alguns casos, foi preferida a significância prática dos achados, em vez da significância estatística.

\section{Resultados}

A apresentação dos resultados realizada neste bloco foi subdividida em quatro seções para facilitar a exposição, entretanto, essas se comunicam e relacionam.

\subsection{Perfil dos sujeitos de pesquisa e alguns motivadores associados ao perfil}

Os 81 respondentes tinham uma idade média de 45,51 anos, com idade mínima de 29 e máxima de 79 anos. 33 eram do sexo feminino e 48 masculino. O maior grupo de respondentes se declarou casado $(66,7 \%)$, seguido de solteiro (12,3\%). Os demais estavam em regime de união estável $(11,1 \%)$, separado $(7,4 \%)$, ou viúvo $(1,2 \%)$. Observa-se que a análise dos dados da pesquisa não identificou diferença de percepções, quando essas variáveis eram cruzadas com as demais variáveis relevantes do estudo.

No que se refere à instituição de ensino a que estão vinculados, atualmente, 52 responderam que trabalham somente na IES caso, oito atuam tanto na IES caso quanto em outra instituição, e 21 se desligaram da IES caso. Perguntados sobre a natureza da sua IES empregadora, a tendência se concentrou em IES comunitária $(64,2 \%)$, seguido de pública (23,5\%). A forma de ingresso na instituição atual, para $49,4 \%$ dos respondentes ocorreu por meio de processo seletivo aberto respondendo a edital específico, para $36,6 \%$ o ingresso ocorreu por convite da IES e $16 \%$ responderam que ingressaram por outras formas. Observa-se que a forma jurídica da IES caso é comunitária, sendo que o ingresso deve ocorrer por meio de Processo 
Seletivo. $\mathrm{O}$ fato dos respondentes informarem que ingressaram por convite ou outras formas tem duas explicações indutivas: a) estão na IES desde período no qual Processo Seletivo não era necessário; e b) participaram de um Processo Seletivo com poucos concorrentes, confirmando a dificuldade de contratação de doutores para uma IES do interior do Estado. Sobre o tempo de trabalho na IES atual, a média de atuação é de oito anos e as respostas estão detalhadas na Tabela 1.

Tabela 1 - Tempo que trabalha na IES atual

\begin{tabular}{lccccccccc}
\hline $\begin{array}{c}\text { Tempo na IES (anos) } \\
\text { IES atual }\end{array}$ & $\begin{array}{c}\text { Não } \\
\text { resposta }\end{array}$ & $\begin{array}{c}\text { Menos de 6 } \\
\text { (depois de } \\
\text { 2009) }\end{array}$ & $\begin{array}{c}\text { De 6 a } \\
\mathbf{1 2}\end{array}$ & $\begin{array}{c}\text { De 12 } \\
\text { a 18 }\end{array}$ & $\begin{array}{c}\text { De 18 } \\
\text { a 24 e }\end{array}$ & $\begin{array}{c}\text { 24 etal } \\
\text { mais }\end{array}$ (quant.) & $\begin{array}{c}\text { Tempo } \\
\text { médio } \\
\text { (anos) }\end{array}$ \\
\hline Outra IES & 1 & $17^{\mathrm{a}}$ & 3 & 0 & 0 & 0 & 21 & $3,40^{\mathrm{b}}$ \\
\hline IES CASO & 4 & 18 & 10 & 6 & 11 & 3 & 52 & 10,59 \\
\hline IES caso e outra IES & 0 & 2 & 3 & $3^{\text {a }}$ & 0 & 0 & 8 & 8,44 \\
\hline Total & $\mathbf{5}$ & $\mathbf{3 7}$ & $\mathbf{1 6}$ & $\mathbf{9}$ & $\mathbf{1 1}$ & $\mathbf{3}$ & $\mathbf{8 1}$ & $\mathbf{8 , 4 7}$ \\
\hline
\end{tabular}

Nota: Qui2 $=25,38, \mathrm{gl}=10,1-\mathrm{p}=99,53 \%$. a Frequência encontrada superior à frequência esperada. bmédia da categoria significativamente menor (teste t à 95\%).

Fonte: Dados da pesquisa.

Observa-se que tempo de vínculo institucional dos respondentes, que atuam em outras IES é significativamente menor que o dos vinculados à IES caso, indicando que a perda de docentes é fato atual e ocorreu de forma acelerada, notadamente, a partir de 2009. Tal dado permite inferir, baseado em Allen et al. (2010), que quando oportuno o docente buscará oportunidades de recolocação. De outro lado, mostra a capacidade de reposição do quadro de doutores, por parte da IES caso. É de se esperar, entretanto, que a persistência deste cenário provoque perdas na produtividade institucional. Observa-se que a partir de 2012, conforme análise documental, a IES caso aprovou cinco cursos de Mestrado e um de Doutorado, o que pode assegurar um quadro mais estável a esta categoria de docentes, se atendida às expectativas que serão reveladas ao longo deste estudo. Quando o docente se sente realizado e reconhecido, os índices de rotatividade podem ser reduzidos.

Sendo o salário importante motivador extrínseco (RIBEIRO; SANT'ANNA, 2015), quando perguntados se possuíam outros rendimentos além do salário da IES, $54,3 \%$ declararam não possuir outro rendimento, fornecendo indícios de que o salário pode ser uma variável chave para retenção destes entrevistados. Dentre os que possuem outro rendimento, $14,8 \%$ disseram que outra fonte é muito importante para a composição de sua renda (Muito importante indica que o sujeito da pesquisa recebe, de outras fontes de renda, valores superiores ao seu salário na IES em que atua). Para estes últimos, provavelmente, outros fatores, além do salário, influenciam para sua permanência na IES. De acordo com Olafsen (2015), estudos sobre a ligação entre dinheiro e motivação demonstram que a quantidade de remuneração não afeta tanto a motivação dos funcionários quanto ao apoio gerencial e a justiça distributiva e processual percebida. 
Atrelado à renda e à qualidade de vida, outro fator intrínseco, que influencia nas decisões dos sujeitos em permanecer (ou não) em uma organização, são as perspectivas de futuro. Perguntados sobre como percebem a si próprios em termos de futuro, os respondentes se posicionaram, conforme Tabela 2.

Tabela 2 - Posicionamento quanto ao futuro (percentual em coluna)

\begin{tabular}{|c|c|c|c|c|}
\hline $\begin{array}{c}\text { IES atual } \\
\text { Posicionamento }\end{array}$ & $\begin{array}{l}\text { Outra } \\
\text { IES }\end{array}$ & $\begin{array}{l}\text { IES } \\
\text { CASO }\end{array}$ & $\begin{array}{l}\text { IES caso e } \\
\text { outra IES }\end{array}$ & TOTAL \\
\hline $\begin{array}{l}\text { Embora deseje acumular patrimônio, me abstenho de alguns } \\
\text { ganhos financeiros adicionais em nome de maior tranquilidade. }\end{array}$ & $28,6 \%$ & $21,2 \%$ & $0,0 \%$ & $21,0 \%$ \\
\hline $\begin{array}{l}\text { Acumular patrimônio não é minha prioridade. Busco qualidade } \\
\text { de vida. }\end{array}$ & $38,1 \%$ & $48,1 \%$ & $62,5 \%$ & $46,9 \%$ \\
\hline $\begin{array}{l}\text { Estou acumulando patrimônio para aproveitar a vida } \\
\text { futuramente. }\end{array}$ & $9,5 \%$ & $21,2 \%$ & $12,5 \%$ & $17,3 \%$ \\
\hline Tenho OUTRA perspectiva. & $23,8 \%$ & $9,6 \%$ & $25,0 \%$ & $14,8 \%$ \\
\hline Total & $100 \%$ & $100 \%$ & $100 \%$ & $100 \%$ \\
\hline
\end{tabular}

Fonte: Dados da pesquisa

Depreende-se da Tabela 2, que 51,9\% dos docentes da IES caso detém uma perspectiva de futuro favorável à mudança de emprego mediante oferta de benefícios financeiros superiores. Isso se acentua para 18 deles $(51,4 \%)$, que não possuem outros rendimentos considerados importantes, além do salário, que recebem da instituição. Dentre os que apontaram "tenho outra perspectiva" (Tabela 02), as respostas apontaram para a busca de qualidade de vida e para a necessidade de estabilidade financeira. Houve também manifestações de desalento com a carreira docente como: "abandonar a carreira docente: carreira em decadência e salários baixos e pouco atraentes" ou manifestação de outra perspectiva como: "constituir uma empresa e me retirar ou reduzir minhas horas na área acadêmica."

Outro fator intrínseco considerado foi a existência de vínculos pessoais do respondente na região, na qual a IES que ele trabalha se situa. Os dados da survey mostram que $40,7 \%$ disseram não possuir nenhum vínculo (além do trabalho na IES) e $59,3 \%$ disseram possuir algum tipo de vínculo. Quando se seleciona apenas os docentes com vínculo atual com a IES caso, verifica-se que 16 dos 52 respondentes não têm outro tipo de vínculo, além do trabalho, o que pode favorecer a sua migração.

\subsection{Motivação para o ingresso e permanência na IES}

Quando perguntados sobre os motivos preferenciais que o mantém trabalhando na atual IES, ao optarem por até duas alternativas dentre uma lista apresentada pelos pesquisadores, os respondentes se posicionaram como expresso na Tabela 3. 
Tabela 3 - Motivos para trabalhar na IES e tipo de fator motivador - Dados
ordenados por ordem de ocorrência

\begin{tabular}{|c|c|c|c|c|}
\hline \multirow[b]{2}{*}{ Motivos para trabalhar na IES } & \multirow[b]{2}{*}{ Frequência } & \multirow[b]{2}{*}{$\begin{array}{l}\text { Percentual } \\
\text { de citações }\end{array}$} & \multicolumn{2}{|c|}{ Tipo de fator motivador } \\
\hline & & & $\begin{array}{r}\text { Intrínseco(I) } \\
\text { Extrínseco(E) }\end{array}$ & $\begin{array}{r}\text { Enquadramento } \\
\mathrm{b}\end{array}$ \\
\hline $\begin{array}{l}\text { Ambiente organizacional } \\
\text { agradável }\end{array}$ & 23 & $28,4 \%$ a & $\mathrm{E}$ & Ambiente \\
\hline Possibilidade de pesquisa & 23 & $28,4 \%^{a}$ & $E$ & Ambiente \\
\hline $\begin{array}{l}\text { Considero uma ótima IES para } \\
\text { trabalhar }\end{array}$ & 15 & $18,5 \%$ & 1 & $\begin{array}{l}\text { Identificação } \\
\text { com o trabalho }\end{array}$ \\
\hline Desenvolvimento Científico & 15 & $18,5 \%$ & 1 & $\begin{array}{c}\text { Desenvolvimento } \\
\text { pessoal }\end{array}$ \\
\hline Nesta IES tenho autonomia & 15 & $18,5 \%$ & $\mathrm{I}$ & Autonomia \\
\hline $\begin{array}{l}\text { Tenho vínculos na região e } \\
\text { preciso estar próximo a eles }\end{array}$ & 14 & $17,3 \%$ & $\mathrm{I}$ & Prazer \\
\hline $\begin{array}{l}\text { Possibilidade de crescimento } \\
\text { profissional }\end{array}$ & 12 & $14,8 \%$ & $E$ & Ambiente \\
\hline Qualidade de vida da região & 11 & $13,6 \%$ & $\mathrm{E}$ & Segurança \\
\hline Pelo salário/remuneração & 10 & $12,3 \%$ & $\mathrm{E}$ & Salário \\
\hline $\begin{array}{l}\text { Devido aos benefícios e } \\
\text { vantagens (Plano de saúde, } \\
\text { bolsa de estudos, plano de } \\
\text { previdência privada) }\end{array}$ & 7 & $8,6 \%$ & $E$ & Benefícios \\
\hline Não resposta & 4 & $4,9 \%$ & & $\begin{array}{c}\text { Sem } \\
\text { categorização }\end{array}$ \\
\hline $\begin{array}{l}\text { Falta de opção de outros locais } \\
\text { de trabalho }\end{array}$ & 4 & $4,9 \%$ & 1 & Reconhecimento \\
\hline Outros Motivos & 2 & $2,5 \%$ & & Diversos \\
\hline $\begin{array}{l}\text { Trabalhar nesta IES confere } \\
\text { status }\end{array}$ & 0 & $0,0 \%$ & 1 & Status \\
\hline Total de observações & 81 & --- & & \\
\hline
\end{tabular}

Nota: A quantidade de citações é superior à quantidade de observações devido às respostas múltiplas (2 no máximo). ${ }^{a}$ Frequência real significativamente superior à frequência teórica. Qui2 $=59,88, \mathrm{gl}=$ $14,1-p=>99,99 \%$. ${ }^{b}$ Tipologia baseada em Klein e Mascarenhas (2016).

Fonte: Dados da pesquisa.

Da Tabela 3 se observa que os fatores extrínsecos, propiciados pelas IES, como ambiente organizacional e condições para realização de pesquisa, merecem destaque e são os principais motivadores para trabalhar nas IES, alinhado a Klein e Mascarenhas (2016). Percebe-se, entretanto, que outros fatores motivacionais extrínsecos relevantes, atrelados à custódia das IES (possibilidade de crescimento, salário, e benefícios), não são considerados elementos motivadores para trabalhar nas IES. Observa-se que os dados da Tabela 3 apresentam a resposta de todos os 81 entrevistados. Quando se consideram apenas os 52 respondentes da IES caso, o ordenamento das motivações é muito similar, com troca de ordenamento entre a segunda e terceira categoria, sendo todas as três primeiras com significativa diferença estatística das demais, pelo teste Qui-quadrado.

A análise dos dados da Tabela 3, quando analisados de forma estratificada, mostra que 0 ambiente organizacional parece ter relevância maior para docentes que pertencem às IES comunitárias, uma vez que $15(37 \%)$ assim o consideram, contra 5 
$(12 \%)$ daqueles respondentes que pertencem às outras IES. Interessante notar que os achados de Marchiori et al. (2006) - de que o status será um fator motivador - não se confirmam neste estudo, uma vez não houve menção a este fator em nenhum dos estratos do estudo.

Sendo o salário um dos fatores extrínsecos relevantes para um grupo de respondentes, é importante observar a percepção dos entrevistados sobre a política salarial da empregadora, conforme Tabela 4.

Tabela 4 - Percepção sobre a política salarial da IES empregadora para Doutores.

\begin{tabular}{lcccc}
\hline $\begin{array}{c}\text { Qual é sua IES atual? } \\
\text { Percepção da Política salarial }\end{array}$ & $\begin{array}{c}\text { Outra } \\
\text { IES }\end{array}$ & $\begin{array}{c}\text { IES } \\
\text { CASO }\end{array}$ & $\begin{array}{c}\text { IES caso e } \\
\text { outra IES }\end{array}$ & TOTAL \\
\hline Abaixo do Mercado & $14,3 \%$ & $30,8 \%$ & $12,5 \%$ & $24,7 \%$ \\
\hline Adequada para a função & $28,6 \%^{\mathrm{a}}$ & $3,8 \%{ }^{\mathrm{b}}$ & $0,0 \%$ & $9,9 \%$ \\
\hline Baixa, mas compatível com as atividades & $9,5 \%$ & $19,2 \%$ & $0,0 \%$ & $14,8 \%$ \\
\hline Dentro do Mercado & $42,9 \%$ & $42,3 \%$ & $62,5 \%$ & $44,4 \%$ \\
\hline Tenho Outra Avaliação & $4,8 \%$ & $3,8 \%$ & $25,0 \%{ }^{\mathrm{a}}$ & $6,2 \%$ \\
\hline TOTAL & $100 \%$ & $100 \%$ & $100 \%$ & $100 \%$ \\
\hline
\end{tabular}

Nota: ${ }^{a}$ Frequência encontrada é superior à frequência esperada. ${ }^{b}$ Frequência encontrada é inferior à frequência esperada Qui2 $=20,35, \mathrm{gl}=8,1-\mathrm{p}=99,09 \%$. Os valores da tabela são os percentuais em coluna estabelecidos sobre 81 observações.

Fonte: Dados da pesquisa.

$\mathrm{Na}$ Tabela 4 se observa clara diferença de percepção quanto à adequação do salário à função, dependendo da IES de vínculo dos respondentes. Isso permite inferir que, embora para efeitos de significância prática os respondentes entendam que a remuneração está dentro da faixa praticada no mercado, parece haver um sentimento de sobrecarga nos docentes da IES caso. Desta maneira, infere-se que a forma como as IES distribuem as atividades entre os seus colaboradores e a percepção de importância, que eles têm a respeito de sua contribuição para a IES, pode afetar os motivos que mantêm os sujeitos de pesquisa trabalhando na IES. A Tabela 5 detalha o conjunto e importância destes motivos. 
Tabela 5 - Fatores que motivam a continuar trabalhando na IES

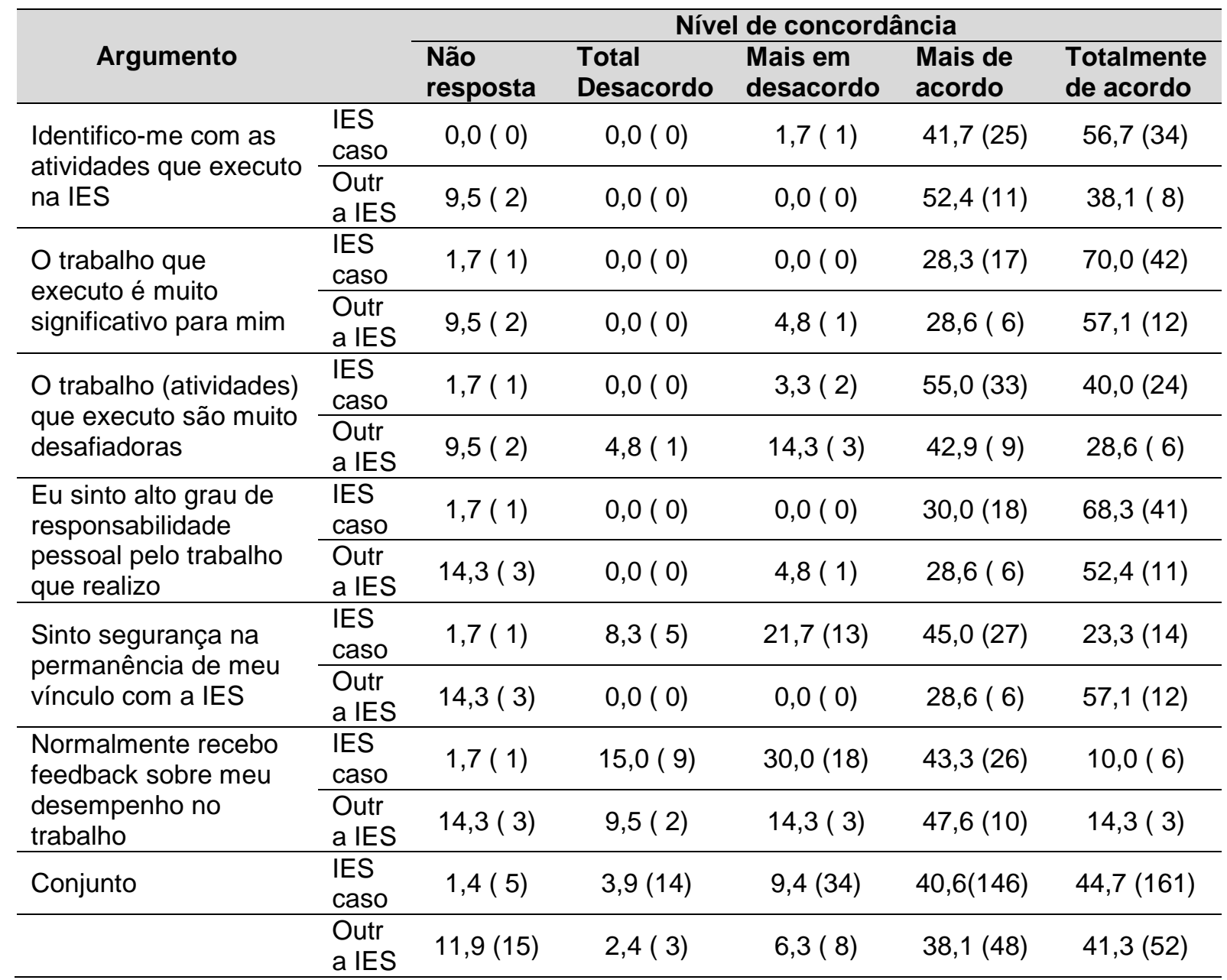

Fonte: Dados da pesquisa.

Note-se que a identificação, significância e responsabilização, para com as atividades realizadas, parecem ser mais relevantes para os entrevistados pertencentes à IES caso, ao passo que a sensação de estabilidade é o maior motivador para aqueles que estão em outras IES.

Um plano de cargos e salários que atenda interesses e necessidades mútuas constitui importante fator de retenção. Quando questionados sobre a existência e adequação de política salarial em sua IES, os sujeitos da pesquisa assim se manifestaram: $14(17,3 \%)$ dos respondentes desconhecem a existência de tal política; $29(39,5 \%)$ entendem que ela não está adequada e 29 (35,8\%) que está adequada. Seis respondentes $(7,4 \%)$ disseram que têm outra avaliação, dentre elas: "Deveria contemplar o novo cenário dos novos Programas de stricto sensu, desta forma, contemplar os resultados da pesquisa como um diferencial de incentivo para a Política de Carreira." E ainda: "A política de carreira leva em consideração as indicações e não o merecimento e competência de cada docente." Também manifestaram preocupação quanto à meritocracia: "A forma como as ascensões de nível em termos do plano de cargos e salário são feitas exige pouco do professor em termos de produtividade científica e práticas de ensino." 
Quando perguntados para avaliar o grau de importância dos benefícios adicionais proporcionados pelas IES, os respondentes se posicionaram, conforme a Tabela 6, diante dos quesitos apresentados.

Tabela 6 - Grau de importância dos benefícios e vantagens proporcionados pela IES, ordenadas em ordem decrescente da Média Escalar

\begin{tabular}{|c|c|c|c|c|c|}
\hline \multirow[b]{2}{*}{ Quesitos } & \multicolumn{4}{|c|}{ Grau de importância - \% ( $n^{\circ}$ de citações) } & \multirow[b]{2}{*}{$\begin{array}{l}\text { Média } \\
\text { Escalar* }\end{array}$} \\
\hline & $\begin{array}{c}\text { Não } \\
\text { resposta ou } \\
\text { Não sabe } \\
\text { avaliar }\end{array}$ & $\begin{array}{c}\text { Sem } \\
\text { importância } \\
\text { ou Pouco } \\
\text { Importante }\end{array}$ & $\begin{array}{l}\text { Importante } \\
\text { ou Muito } \\
\text { Importante }\end{array}$ & Total & \\
\hline Autonomia & $7,4(6)$ & $6,2(5)$ & $86,4(70)$ & $100(81)$ & 4,46 \\
\hline $\begin{array}{l}\text { Comunicação } \\
\text { com colegas }\end{array}$ & $14,8(12)$ & $2,5(2)$ & $82,7(67)$ & $100(81)$ & 4,41 \\
\hline $\begin{array}{l}\text { Relacionamento } \\
\text { com colegas de } \\
\text { trabalho }\end{array}$ & $14,8(12)$ & $1,2(1)$ & $84,0(68)$ & $100(81)$ & 4,40 \\
\hline Salário & $2,5(2)$ & $2,5(2)$ & $95,1(77)$ & $100(81)$ & 4,39 \\
\hline $\begin{array}{l}\text { Flexibilidade do } \\
\text { horário de } \\
\text { trabalho }\end{array}$ & $11,1(9)$ & $7,4(6)$ & $81,5(66)$ & $100(81)$ & 4,39 \\
\hline $\begin{array}{l}\text { Relacionamento } \\
\text { com superiores } \\
\text { imediatos }\end{array}$ & $11,1(9)$ & $2,5(2)$ & $86,4(70)$ & $100(81)$ & 4,31 \\
\hline $\begin{array}{l}\text { Recursos para } \\
\text { pesquisa (tempo } \\
\text { e dinheiro) }\end{array}$ & $12,3(10)$ & $8,6(7)$ & $79,0(64)$ & $100(81)$ & 4,27 \\
\hline $\begin{array}{l}\text { Forma positiva } \\
\text { de Comunicação } \\
\text { com superiores }\end{array}$ & $13,6(11)$ & $7,4(6)$ & $79,0(64)$ & $100(81)$ & 4,17 \\
\hline $\begin{array}{l}\text { Reconhecimento } \\
\text { por parte dos } \\
\text { superiores }\end{array}$ & $12,3(10)$ & $9,9(8)$ & $77,8(63)$ & $100(81)$ & 4,15 \\
\hline $\begin{array}{l}\text { Espaço físico de } \\
\text { trabalho } \\
\text { presencial }\end{array}$ & $11,1(9)$ & 9,9 ( 8) & $79,0(64)$ & $100(81)$ & 4,08 \\
\hline $\begin{array}{l}\text { Nível e forma de } \\
\text { cobrança de } \\
\text { resultados }\end{array}$ & $14,8(12)$ & $9,9$ ( 8$)$ & $75,3(61)$ & $100(81)$ & 3,95 \\
\hline $\begin{array}{l}\text { Apoio para a } \\
\text { docência }\end{array}$ & $12,3(10)$ & $17,3(14)$ & $70,4(57)$ & $100(81)$ & 3,91 \\
\hline $\begin{array}{l}\text { Recursos para } \\
\text { publicação }\end{array}$ & $18,5(15)$ & $18,5(15)$ & $63,0(51)$ & $100(81)$ & 3,88 \\
\hline $\begin{array}{l}\text { Recursos para } \\
\text { participar de } \\
\text { eventos } \\
\text { externos }\end{array}$ & $12,3(10)$ & $24,7(20)$ & $63,0(51)$ & $100(81)$ & 3,74 \\
\hline $\begin{array}{l}\text { Condições de } \\
\text { segurança e } \\
\text { ergonomia }\end{array}$ & $18,5(15)$ & $16,0(13)$ & $65,4(53)$ & $100(81)$ & 3,70 \\
\hline $\begin{array}{l}\text { Plano } \\
\text { previdenciário }\end{array}$ & $12,3 \%(10)$ & $22,2 \%(18)$ & $65,4 \%(53)$ & $100 \%(81)$ & 3,62 \\
\hline $\begin{array}{l}\text { Atendimento } \\
\text { psicológico }\end{array}$ & $37,0(30)$ & $48,1(39)$ & $14,8(12)$ & $100(81)$ & 2,28 \\
\hline $\begin{array}{l}\text { Atendimento } \\
\text { odontológico }\end{array}$ & $32,1(26)$ & $49,4(40)$ & $18,5(15)$ & $100(81)$ & 2,27 \\
\hline Conjunto & $15,0(218)$ & $14,7(214)$ & $70,4(1026)$ & $100(1458)$ & 3,77 \\
\hline
\end{tabular}

REUNA, Belo Horizonte - MG, Brasil, v.23, n.l, p.54-74, Jan. - Mar.. 2018 - ISSN 2179-8834 
A Tabela 6 demonstra que elementos externos e internos são relevantes na percepção dos respondentes da pesquisa, corroborando Klein e Mascarenhas (2016). Observa-se, entretanto, que alguns fatores extrínsecos como atendimento psicológico e odontológico não são considerados relevantes para os sujeitos da pesquisa. Isto, talvez, se deva ao acesso a estes serviços que este grupo possui por meios próprios. Também é interessante notar que o reconhecimento (representado pela autonomia e flexibilidade conferida, e o salário recebido), bem como o relacionamento (representado pela forma de comunicação e relacionamento com colegas e superiores) representam os elementos de maior importância para este grupo, evidenciando que o bem-estar no trabalho é importante para os sujeitos da pesquisa. O bem-estar tem sido apontado como significativo para a continuidade na carreira e para atribuir significado ao trabalho (FERNÁNDEZ, PÉREZ E GONZÁLEZ, 2013).

Os respondentes foram convidados a apontar a existência de alguma razão adicional, que os motiva e fortalece seu vínculo com a IES na qual atua. Dentre as respostas, salienta-se: "Relacionamento com a comunidade externa; Desafio profissional constante, portanto, atividade dinâmica; Atividades em grupo". E ainda "estabilidade de emprego," pois: "[...] o maior problema que me deparo é a insegurança em estar empregado no próximo ano ou semestre. Todo semestre é uma luta para manutenção da carga horária." Há também o sentimento de pertença motivando a permanência: "Participei de sua construção enquanto universidade". Este último depoimento está alinhado com a Tabela 7.

\section{Tabela 7 - Motivos para trabalhar na IES, em função da idade do respondente}

\begin{tabular}{|c|c|c|c|c|c|c|}
\hline \multirow[b]{2}{*}{ Motivos para trabalhar na IES ${ }^{a}$} & \multicolumn{5}{|c|}{ Idade (estratificada por faixas geracionais) } & \multirow{2}{*}{$\begin{array}{l}\text { Idade } \\
\text { Média }^{b}\end{array}$} \\
\hline & $\begin{array}{l}\text { Não } \\
\text { resposta }\end{array}$ & $\begin{array}{l}\text { Menos } \\
\text { de } 32\end{array}$ & $\begin{array}{l}\text { De } 32 \\
\text { a } 48\end{array}$ & $\begin{array}{l}\text { De } 48 \\
\text { a } 68\end{array}$ & $\begin{array}{l}68 \mathrm{e} \\
\text { mais }\end{array}$ & \\
\hline Não resposta & 0 & 0 & 3 & 1 & 0 & 39,75 \\
\hline Ambiente organizacional agradável & 0 & 0 & 10 & 12 & 1 & $50,48^{*}$ \\
\hline $\begin{array}{l}\text { Considero uma ótima IES para } \\
\text { trabalhar }\end{array}$ & 0 & 0 & 7 & 8 & 0 & 46,47 \\
\hline Desenvolvimento Científico & 0 & 0 & 9 & 5 & 1 & 48,00 \\
\hline $\begin{array}{l}\text { Devido aos benefícios e vantagens } \\
\text { (Plano de saúde, bolsa de estudos, } \\
\text { plano de previdência privada }\end{array}$ & 0 & 1 & 2 & 4 & 0 & 45,86 \\
\hline $\begin{array}{l}\text { Falta de opção de outros locais de } \\
\text { trabalho }\end{array}$ & 0 & 1 & 2 & 1 & 0 & 41,00 \\
\hline Nesta IES tenho autonomia & 0 & 0 & 12 & 2 & 1 & 44,07 \\
\hline Pelo salário/remuneração & 0 & 0 & 6 & 4 & 0 & 45,70 \\
\hline $\begin{array}{l}\text { Possibilidade de crescimento } \\
\text { profissional }\end{array}$ & 0 & 0 & 8 & 4 & 0 & 45,00 \\
\hline Possibilidade de pesquisa & 0 & 0 & 14 & 8 & 1 & 45,70 \\
\hline Qualidade de vida da região & 1 & 1 & 6 & 3 & 0 & 43,20 \\
\hline $\begin{array}{l}\text { Tenho vínculos na região e preciso } \\
\text { estar próximo a eles }\end{array}$ & 1 & 1 & 8 & 4 & 0 & 42,62 \\
\hline Trabalhar nesta IES confere status & 0 & 0 & 0 & 0 & 0 & - \\
\hline Outros Motivos & 0 & 0 & 1 & 1 & 0 & 48,50 \\
\hline Total & 2 & 4 & 88 & 57 & 4 & 45,84 \\
\hline
\end{tabular}

Notas: aOs valores da tabela são as quantidades de citações de cada dupla de categorias. ${ }^{b}$ Os valores da tabela são as médias calculadas sem considerar as não-respostas. *média significativamente diferente (teste t) do conjunto da amostra (ao risco de 95\%).

Fonte: Dados da pesquisa. 
$\mathrm{Na}$ Tabela 7 percebe-se que os respondentes, que têm idade média mais elevada, têm a percepção de que o ambiente organizacional se constitui em um dos principais motivos para trabalhar na IES. A Tabela foi elaborada considerando a divisão das faixas etárias: a) geração tradicional, aqueles indivíduos que têm mais de 68 anos, b) baby boomers são aqueles que têm de 48 a 68, c) geração X, com idade entre 32 a 48 anos, e d) geração $Y$, com menos de 32 anos de idade. A geração $Z$ não é mencionada, pois nenhum entrevistado possui idade inferior a 23 anos. Pode-se notar que a maioria dos entrevistados pertence à geração $Y(57 \%)$, seguido dos baby boomers com $37 \%$. Isto deve ser considerado sobre os efeitos da retenção de talentos, uma vez que as gerações possuem comportamentos e preferências distintos. Percebe-se que a Possibilidade de Pesquisa e Autonomia são fatores apontados com maior destaque pela geração $\mathrm{Y}$ (majoritária).

\subsection{Motivação e desmotivação para atuar no stricto sensu}

Quando se cruzam os motivos para trabalhar na IES, com a motivação para atuar em Mestrados e lou Doutorados, percebe-se coerência entre as respostas, demonstrando que o objetivo maior de um doutor, dentro de uma IES, é atuar no Stricto sensu. A possibilidade de realizar pesquisa é a mais relevante, seguida da produção de artigos, docência e autorrealização. Por outro lado, ao serem perguntados acerca do que os desmotivariam a continuar trabalhando na atual IES, os sujeitos de pesquisa apontaram, principalmente: a questão salarial, a falta de segurança (estabilidade) de que a IES mantenha o vínculo, o baixo incentivo à pesquisa, a falta de reconhecimento de seu trabalho. Apontaram também, embora com menor ênfase, questões relacionadas ao gerenciamento de pessoas, resultando em desmotivação devido a perceber: "preferências por alguns docentes em detrimento de outros, sem levar em consideração a competência técnica. E privilégios concedidos a alguns." O clima organizacional e as relações interpessoais com colegas e superiores também foram apontados como elementos desmotivadores.

Se observadas as respostas somente dos respondentes, que eram vinculados a IES foco do estudo, os motivos principais, que levaram a deixar de trabalhar nela estão agrupados na Tabela 8.

Tabela 8 - Motivos que levaram os docentes a sair da IES caso (respostas ordenadas por frequência de citações)

\begin{tabular}{lcc}
\hline \multicolumn{1}{c}{ Motivos sair da IES caso } & Frequência & $\begin{array}{c}\text { Percentual de } \\
\text { citações }\end{array}$ \\
\hline Falta de estabilidade & 12 & $57,1 \%$ \\
\hline Baixo incentivo à pesquisa & 9 & $42,9 \%$ \\
\hline Outros motivos & 7 & $33,3 \%$ \\
\hline Volume excessivo de atividades & 2 & $9,5 \%$ \\
\hline Ambiente de trabalho desfavorável & 2 & $9,5 \%$ \\
\hline Não resposta & 1 & $4,8 \%$ \\
\hline $\begin{array}{l}\text { Relacionamento com os colegas do colegiado } \\
\text { desfavorável }\end{array}$ & 1 & $4,8 \%$ \\
\hline Relacionamento ruim com o Coordenador do Mestrado & 0 & $0,0 \%$ \\
\hline Total & $\mathbf{2 1}$ & $\mathbf{1 0 0} \%$ \\
\hline
\end{tabular}

Nota: A quantidade de citações é superior à quantidade de observações devido às respostas múltiplas (4 no máximo).

Fonte: Dados da pesquisa.

RELNA, Belo Horizonte - MG, Brasil, v.23, n.I, p.54-74, Jan. - Mar.. 2018 - ISSN 2179-8834 
A falta de estabilidade se constitui na razão mais citada por estes egressos da IES caso, seguido do entendimento de que havia baixo incentivo à pesquisa e de outros motivos. Entre os outros motivos de insatisfação com a IES foco deste estudo, na visão dos respondentes, está o descontentamento com o salário recebido: "Pagam salário de especialista para doutores iniciantes. Isso é exploração!" e também apareceram citações como: "Sentimento de falta de confiança por parte dos gestores;" ou ainda "poucas horas destinadas à pesquisa e poucos recursos destinados para a participação em eventos de aprimoramento; [...] A instituição focada em ensino (graduação), sem incentivo para a pesquisa"; e "exigência de trabalhar com mais disciplinas." Estes elementos de desmotivação apareceram, especificamente, entre os respondentes vinculados aos Programas de Mestrado e Doutorado da IES caso, por falas como a que segue: "os professores do stricto sensu deveriam ter grande diferencial em termos salariais".

Dentre os motivos que estimulam os sujeitos da pesquisa a atuar em Mestrado e/ou Doutorado, os dados coletados estão na Tabela 9, sendo que o respondente poderia optar por até duas alternativas.

\section{Tabela 9 - Fatores que motivam a trabalhar na IES nos Mestrados e/ou Doutorados}

\begin{tabular}{lcc}
\hline \multicolumn{1}{c}{$\begin{array}{c}\text { Fatores que motivam a atuar } \\
\text { nos Mestrados e/ou Doutorados }\end{array}$} & Frequência & $\begin{array}{c}\text { Percentual de } \\
\text { citações }\end{array}$ \\
\hline Não resposta & 28 & $34,6 \%$ \\
\hline Autorrealização & 12 & $14,8 \%$ \\
\hline Possibilidade de desenvolver pesquisa & 41 & $50,6 \%$ \\
\hline Docência para alunos de mestrado/doutorado & 13 & $16,0 \%$ \\
\hline Possibilidade de ministrar menos aulas na graduação & 5 & $6,2 \%$ \\
\hline Produção de artigos científicos & 18 & $22,2 \%$ \\
\hline Maior disponibilidade de recursos financeiros & 4 & $4,9 \%$ \\
\hline Maior disponibilidade de recursos (não financeiros) & 0 & $0,0 \%$ \\
\hline Maior autonomia para desenvolver meu trabalho & 8 & $9,9 \%$ \\
\hline $\begin{array}{l}\text { Trabalhar nestes cursos confere reconhecimento de } \\
\text { competência }\end{array}$ & 2 & $2,5 \%$ \\
\hline $\begin{array}{l}\text { Possibilidade de exercer outra atividade (consultoria, } \\
\text { etc.) }\end{array}$ & 0 & $0,0 \%$ \\
\hline Maior autonomia para saídas a compromissos & 0 & $0,0 \%$ \\
externos & 2 & $2,5 \%$ \\
\hline Outros & $\mathbf{8 1}$ & $\mathbf{1 0 0} \%$ \\
\hline Total & & \\
\hline
\end{tabular}

Nota: O número de não respostas é elevado, devido ao fato de o questionamento ser direcionada a quem atua ou atuou no Stricto Sensu. O Número de citações é superior à quantidade de observações devido a se tratar de respostas múltiplas (2 no máximo).

Fonte: Dados da pesquisa.

Observa-se que o principal motivo para atuar no stricto sensu é a possibilidade de realizar pesquisa, seguido da produção de artigos. Isto aponta que os docentes, que atuam neste nível, valorizam a produção do conhecimento, e que esses fatores parecem se constituir em aspecto intrínseco da motivação, mas podem ser estimulados por fatores externos, por meio da oferta de condições favoráveis para tal. Os que citaram outras razões mencionaram: pagamento de horas para a pesquisa e fazer parte de grupos de pesquisa. 
Já os fatores que desmotivam a atuar em Mestrado/ Doutorado da IES, os principais apontados estão expressos na Tabela 10.

\section{Tabela 10 - Fatores que desmotivam a trabalhar em Mestrado e/ou Doutorado na IES}

\begin{tabular}{lcc}
\hline \multicolumn{1}{c}{ Fatores que desmotivam } & Frequência & $\begin{array}{c}\text { Percentual de } \\
\text { citações }\end{array}$ \\
\hline Não resposta & 29 & $35,8 \%$ \\
\hline Excesso de metas para publicação & 18 & $22,2 \%$ \\
\hline Excesso de atribuições (fora dos objetivos do programa) & 20 & $24,7 \%$ \\
\hline Excesso de atividades burocráticas & 20 & $24,7 \%$ \\
\hline Excesso de orientação & 3 & $3,7 \%$ \\
\hline Falta de compensação financeira & 25 & $30,9 \%$ \\
\hline Outros & 4 & $4,9 \%$ \\
\hline Total & $\mathbf{8 1}$ & $\mathbf{1 0 0} \%$ \\
\hline
\end{tabular}

Nota: O número de não respostas é elevado, devido ao fato de o questionamento ser direcionado para quem atua ou atuou no Stricto Sensu. O Número de citações é superior à quantidade de observações devido a se tratar de respostas múltiplas (2 no máximo).

Fonte: Dados da pesquisa.

A Tabela 10 sinaliza que a falta de compensação financeira para o docente atuar no stricto sensu se constituiu em fator inibidor da motivação. Curiosamente, apesar de um dos principais fatores motivadores para atuar neste nível seja produzir artigos (Tabela 8), como as metas colocadas pelo sistema de avaliação, externo a IES, são exigentes, a produção científica acaba, em contraponto, sendo percebida como fonte de estresse pelos pesquisadores. Também é percebido como importante fator de desmotivação, o excesso de atribuições fora das atividades finalísticas do programa e/ou aquelas mais burocráticas.

\section{Considerações finais}

O objetivo geral do estudo foi compreender o que motiva o docente a ingressar e a permanecer atuando em IES Comunitária e em Programas de pósgraduação stricto sensu (Mestrado e Doutorado). A pesquisa foi desenvolvida por meio de estudo de caso aplicado a IES comunitária do Estado de Santa Catarina. Foram aplicados 81 questionários e foi realizada a análise de documentos. Os resultados observados demonstram que entre principais fatores que motivam docentes a ingressar e/ou permanecer trabalhando em IES estão: a possibilidade de desenvolver pesquisa e a autonomia, que podem usufruir. Entre os fatores que mais os desmotivam estão àqueles ligados ao salário e ao ambiente de trabalho, notadamente, o relacionamento interpessoal.

Se por um lado, a busca por estabilidade levou um grupo de docentes da IES caso a se desligar dela, motivados pela abertura de concursos em instituições públicas, por outro o estudo permite observar que aqueles que optaram por atuar na IES estudada demandam maiores investimentos dela em elementos, que possam favorecer a motivação extrínseca como uma política salarial percebida pelos sujeitos como condizente com sua atuação no stricto sensu, a maior valorização da pesquisa e liberação, no limite do possível, de atividades rotineiras e meramente burocráticas. 
Desta maneira, o estudo tem como limitação não apresentar possibilidades concretas para equacionar os aspectos desmotivantes, apontando para a necessidade de pesquisa complementar para elaborar, a partir deste levantamento, estratégias que possam gerar resultados favoráveis para a retenção de docentes nos quadros da IES caso, tendo como base aqueles fatores que os sujeitos de pesquisa apontaram como preferenciais. Para além do caso analisado, o estudo contribui para a reflexão daquelas instituições que tenham as mesmas configurações da IES caso, atentando para a necessidade das IES estabelecerem política de atração e de retenção de docentes, sobretudo, direcionada para os doutores, para atuarem na Pósgraduação (Mestrados e Doutorados).

\section{Referências}

AGAPITO, P. R.; POLIZZI FILHO, A.; SIQUEIRA, M. M. M. Bem-Estar no Trabalho e Percepção de Sucesso na Carreira como Antecedentes de Intenção de Rotatividade. Revista de Administração Mackenzie, São Paulo, v. 16, n. 6, p. 71-93, 2015.

AGNOLIN, C. T. Retenção do Conhecimento Organizacional. Dissertação (Mestrado). Mestrado Profissional em Administração. Universidade do Oeste de Santa Catarina, 2016.

BRAGA JÚNIOR, S. S.; SANTOS, R. R.; CARVALHO, J. S.; SILVA, G. P.; SILVA, D. Possibilidades entre motivação e produtividade: um estudo de caso no Alto Tietê. Sociedade, Contabilidade e Gestão, v. 8, n. 3, p. 91-104, 2013.

BRAVO, J. et al. Measuring Career Orientations in the Era of the Boundaryless Career. Journal of Career Assessment, v. 25, n. 3, p. 502-525, 2017.

BRASIL. Ministério da Educação. Coordenação de Aperfeiçoamento de Pessoal de Nível Superior. Plano Nacional de Pós-Graduação (PNPG) 2011 - 2020. Brasília: CAPES, 2011.

BERGAMINI, C. W. Motivação: uma viagem ao centro do conceito. RAE, v.1, n.2, p. 63-67, Nov 2002 a Jan 2003.

BUSER, Thomas; NIEDERLE, Muriel; OOSTERBEEK, Hessel. Gender, competitiveness, and career choices. The Quarterly Journal of Economics, v. 129, n. 3, p. 1409-1447, 2014.

BZUNECK, J. A.; GUIMARÃES, S. E. R. Estilos de professores na promoção da motivação intrínseca: reformulação e validação de instrumento. Psicologia: Teoria e Pesquisa. Out-Dez, Vol. 23, n. 4, p. 415-422, 2007. Disponível em: Acesso em: 19 Mai. 2016.

CERIBELI, H. B.; GONÇALVES, D. C. S. Uma Análise da Relação entre Valores Organizacionais, Motivação e Intenção de Abandono da Organização. Reuna, Belo Fortaleza, v. 20, n. 4, p. 51-66, 2015.

CLARO, J. A. C. S.; PROFETA, R. A. Programas de benefícios sociais para docentes no ensino superior brasileiro como forma de reter talentos: um estudo exploratório. Avaliação (Campinas), Sorocaba, v. 20, n. 1, p. 189-223, Mar. 2015. 
Disponível em :<http://www.scielo.br/scielo.php?script=sci_arttext\&pid=S141440772015000100189\&Ing=en\&nrm=iso>. Acesso em: 07 Fev. 2017.

FERnÁNDEZ, M. P.; PÉREZ, M. A.; GONZÁLEZ, H. Efecto del fluzo y el afecto positivo en el bienestar psicológico. Boletín de Psicología, n. 107, p. 71-90, mar. 2013.

GARCIA, O. P. G.; COLTRE, S. M. A Gestão do Conhecimento como Fator Determinante na Retenção dos Colaboradores na Empresa: Um Estudo de Caso em uma Organização do Ramo Moveleiro. Brazilian Business Review, v. 14, n. 2, p. 182-203, 2017.

GOMES, A. A. P.; QUELHAS, O. L. G. Motivação dos recursos humanos no Serviço Público. Revista Eletrônica de Administração - REAd, ed. 35, v. 9, n. 5, set/out. 2003.

GODOI, C. K.; FREITAS, S. M. F.; CARVALHO, T. B. Motivação na aprendizagem organizacional: construindo as categorias afetiva, cognitiva e social. Revista de Administração Mackenzie, v. 12, n. 2, art. 159, p. 30-54, 2011.

KLEIN, F. A.; MASCARENHAS, A. O. Motivação, satisfação profissional e evasão no serviço público: o caso da carreira de especialistas em Políticas Públicas e Gestão Governamental. Revista de Administração Pública, v. 50, n. 1, p. 17-39, 2016.

MARCHIORI, P. Z. et al. Fatores motivacionais da comunidade científica para publicação e divulgação de sua produção em revistas científicas. SIMPÓSIO REGIONAL DA PESQUISA EM COMUNICAÇÃO, v. 7, 2006.

OLAFSEN, A.H.; HALVARI, H.; FOREST, J.; DECI, E.L. Show them the money? The role of pay, managerial need support, and justice in a self-determination theory model of intrinsic work motivation. Scandinavian journal of psychology, v. 56, n. 4, p. 447457, 2015.

REUBEN, E.; SAPIENZA, P.; ZINGALES, L. How stereotypes impair women's careers in science. Proceedings of the National Academy of Sciences, v. 111, n. 12, p. 4403-4408, 2014.

RIBEIRO, R. M.; NUNES, S. C.; SANT'ANNA, A. S. Retenção de pessoas: um estudo em empresa pública do Estado de Minas Gerais. Revista Economia \& Gestão, v. 15, n. 38, p. 110-134, 2015.

SIQUEIRA, W. R.; ALVES, L. C. F. Rotatividade de Professores Universitários: o Caso de um Campus Fora da Sede. Revista de Administração, Contabilidade e Economia da FUNDACE, v. 7, n. 2, p. 94-107, 2016.

TAYLOR, G. et al. A self-determination theory approach to predicting school achievement over time: The unique role of intrinsic motivation. Contemporary Educational Psychology, v. 39, n. 4, p. 342-358, 2014.

YIN, R. K. Estudo de caso: planejamento e métodos. 4ํㅡㄹ ed. Porto Alegre: Bookman, 2010. 